\title{
Rapid reaction sintering of silicon carbide using Nd:YAG laser
}

\author{
Satoshi SUEHIRO ${ }^{1 \dagger}{ }^{\dagger}$ and Teiichi KIMURA ${ }^{1}$ \\ ${ }^{1}$ Materials Research and Development Laboratory, Japan Fine Ceramics Center, \\ 2-4-1 Mutuno, Atsuta-ku, Nagoya 456-8587, Japan
}

\begin{abstract}
Reaction sintering of silicon carbide ( $\mathrm{SiC}$ ) using a continuous-wave Nd:YAG laser as a heating source was investigated. The laser was used to irradiate pellets of a stoichiometric powder mixture of Si and $\mathrm{C}$ under Ar gas flow. At an appropriate laser power, a dense SiC layer was formed consisting of grains with a size of 100-500 $\mathrm{nm}$; this layer was several micrometers thick. At lower laser power, fine grains of $\mathrm{SiC}$ were formed and dispersed in the unreacted Si-C matrix. On the other hand, at higher power, larger faceted SiC grains (1-3 $\mu$ m) were formed. (C)2019 The Ceramic Society of Japan. All rights reserved.
\end{abstract}

Key-words : Silicon carbide, Direct laser sintering, Reaction sintering

[Received November 12, 2018; Accepted April 22, 2019]

Silicon carbide $(\mathrm{SiC})$ is a promising structural material due to its low weight and excellent mechanical properties. SiC has been extensively investigated for various applications, such as components in gas turbines and in semiconductor manufacturing apparatus. ${ }^{1)-4)}$ However, the direct sintering of $\mathrm{SiC}$ is difficult because this material has no melting point under atmospheric pressure and sublimates around $2500^{\circ} \mathrm{C}$. Therefore, reaction sintering (RS) techniques have been widely used to obtain $\mathrm{SiC}$ parts, where molten $\mathrm{Si}$ is infiltrated into porous $\mathrm{SiC}-\mathrm{C}$ precursor bodies. RS is an advantageous industrial process, because the reaction temperature is relatively low (around $1400^{\circ} \mathrm{C}$ ), and close to the melting point of Si. Reaction-sintered $\mathrm{SiC}$ (RS-SiC) usually contains $5-10$ vol.\% $\mathrm{Si}$, because the molten Si infiltrates through open pores into the bulk of the sintered body and unreacted Si solidifies in the pores. It is known that the mechanical properties of RS-SiC at high temperature are strongly affected by this residual $\mathrm{Si}^{5), 6}$ Hence, in order to improve the mechanical properties of $\mathrm{SiC}$ at high temperature, minimizing the residual Si content is necessary. Recently, ceramics manufacturing processes using a high-intensity laser as a heating source were proposed ${ }^{7)-10)}$ for the manufacture of $\mathrm{Al}_{2} \mathrm{O}_{3} / \mathrm{SiO}_{2}$ composites, ${ }^{11)} \mathrm{Al}_{2} \mathrm{O}_{3} / \mathrm{Y}_{3} \mathrm{Al}_{5} \mathrm{O}_{12}$ eutectic composites, ${ }^{12)}$ Ti-Si-C MAX-phase ceramics, ${ }^{13}$ ) and $\mathrm{WC}-\mathrm{Co}$ cemented carbides. ${ }^{14)}$ In particular, Mayers et al. reported that porous Si-bonded $\mathrm{SiC}(\mathrm{Si}-\mathrm{SiC})$ was formed using direct laser sintering; after laser sintering, the sample was impregnated with phenolic resin in the furnace. ${ }^{15)}$ However, in this study, we investigated the formation of $\mathrm{SiC}$ from $\mathrm{C}$ and $\mathrm{Si}$ using laser sintering, and analyzed the microstructures and crystalline phases of the RS-SiC.

\footnotetext{
Corresponding author: S. Suehiro; E-mail: s_suehiro@jfcc. or.jp
}

Reagent-grade Si (purity: 99\%; average particle size: $5 \mu \mathrm{m}$; Kojundo Chemical Laboratory) and C (particle size: $<100 \mathrm{~nm}$; Sigma-Aldrich) powders were used as starting materials. They were weighed at a 1:1 molar ratio and ball-milled in ethanol media for $24 \mathrm{~h}$. After drying at $120^{\circ} \mathrm{C}$ in air, the powder mixture was uniaxially pressed at $10 \mathrm{MPa}$ into pellets $(10 \mathrm{~mm}$ in diameter, $1 \mathrm{~mm}$ in thickness), followed by cold isotactic pressing at $245 \mathrm{MPa}$. The experimental setup for this study is shown in Fig. 1(a). The pellet was placed in a vacuum chamber and irradiated from above by a continuous-wave Nd:YAG laser $[\lambda=$ $1064 \mathrm{~nm}$; laser power density $\left.\left(P_{\mathrm{L}}\right)=5,10,12 \mathrm{~kW} / \mathrm{cm}^{2}\right]$ through a quartz window under a flow of Ar. The pressure was maintained at $10^{4} \mathrm{~Pa}$ during heating. The laser scanned the entire surface of the pellet using a Galvanomirror, as shown in Fig. 1(b). Microstructures were observed by field-emission scanning electron microscopy (FE-SEM; SU-8000, HITACHI), and crystalline phases were analyzed by X-ray diffraction (XRD; RINT-2000, Rigaku).

Figures 2(a)-2(d) shows the surface SEM images of the samples before and after single laser scanning (the total irradiation time was about $10 \mathrm{~s}$ ). At $P_{\mathrm{L}}=5 \mathrm{~kW} / \mathrm{cm}^{2}$ [Fig. 2(b)], faceted grains $100-500 \mathrm{~nm}$ in diameter were dispersed in a porous matrix. At $P_{\mathrm{L}}=10 \mathrm{~kW} / \mathrm{cm}^{2}$ [Fig. 2(c)], the grain size increased to $1 \mu \mathrm{m}$. At $P_{\mathrm{L}}=12$ $\mathrm{kW} / \mathrm{cm}^{2}$ [Fig. 2(d)], larger faceted grains $1-3 \mu \mathrm{m}$ in diameter were clearly observed. The relative fraction of the matrix material observed in these SEM images clearly decreases with increasing $P_{\mathrm{L}}$.

Figure 3 shows XRD patterns of the (a) precursor powder; and RS-SiC samples sintered at (b) $5 \mathrm{~kW} / \mathrm{cm}^{2}$, (c) $10 \mathrm{~kW} / \mathrm{cm}^{2}$, and (d) $12 \mathrm{~kW} / \mathrm{cm}^{2}$. Patterns of the samples. $\mathrm{SiC}$ was formed in the irradiated samples $\left(P_{\mathrm{L}}=5-12\right.$ $\mathrm{kW} / \mathrm{cm}^{2}$ ), and diffraction peaks from the unreacted $\mathrm{Si}$ 
(a)

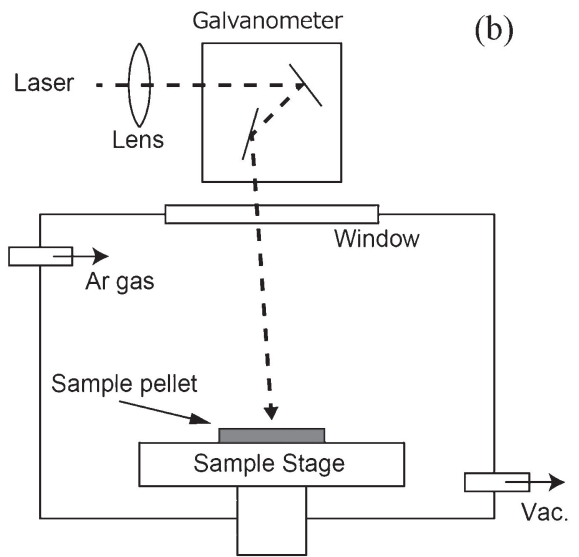

(b)

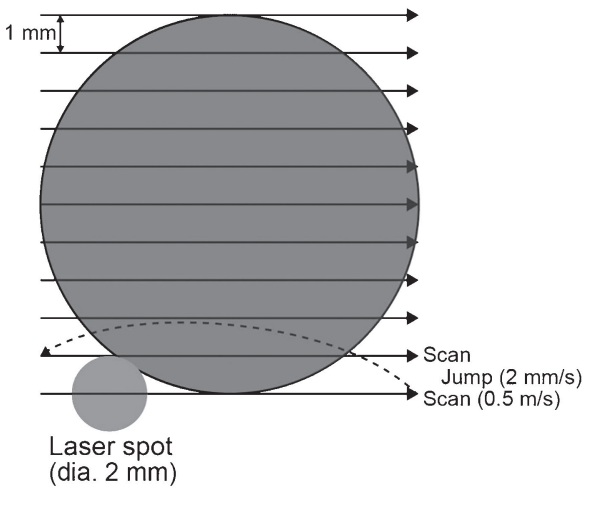

Fig. 1. Schematic illustrations of the (a) direct laser heating apparatus and (b) laser scanning conditions.
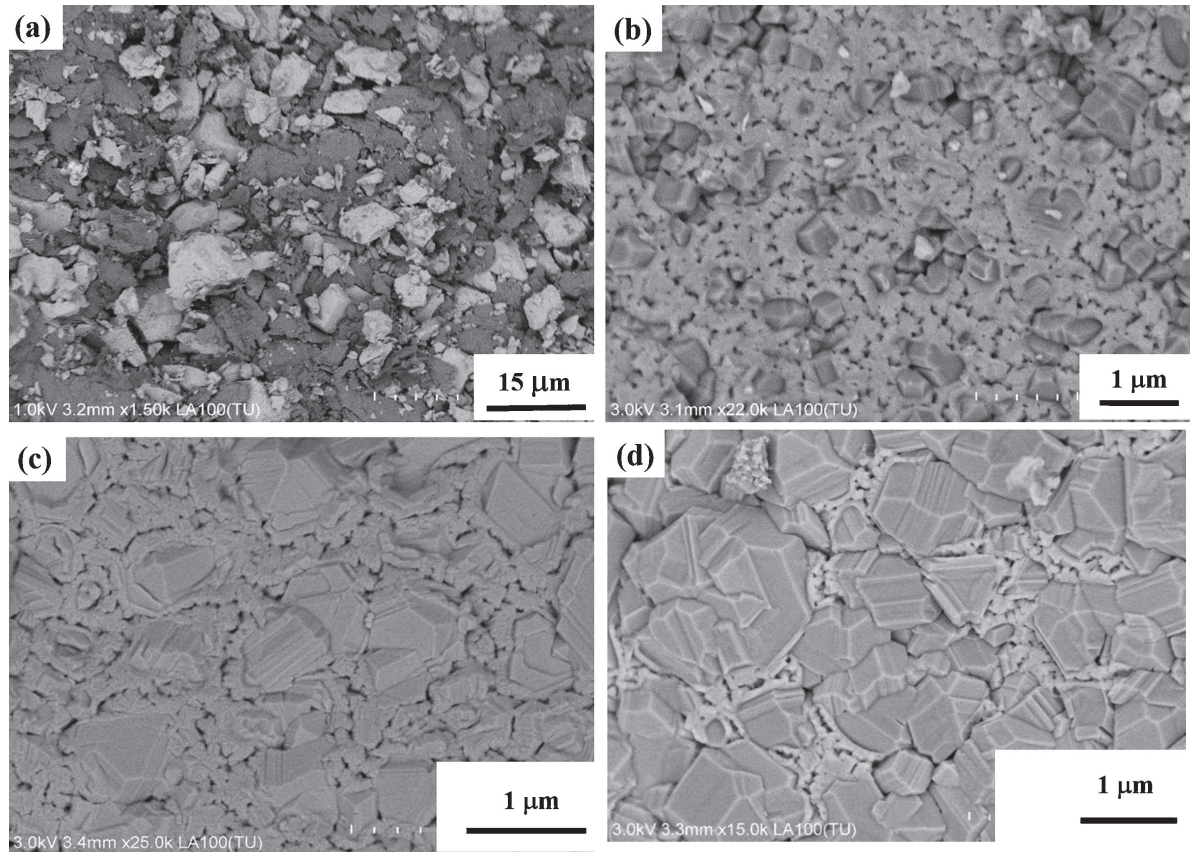

Fig. 2. SEM images of the surfaces of the (a) precursor powder; and RS-SiC samples sintered at (b) $5 \mathrm{~kW} / \mathrm{cm}^{2}$, (c) $10 \mathrm{~kW} / \mathrm{cm}^{2}$, and (d) $12 \mathrm{~kW} / \mathrm{cm}^{2}$.

and $\mathrm{C}$ decreased with increasing $P_{\mathrm{L}}$. The SEM and XRD results indicate that the faceted grains and the matrix in Figs. 2(b)-2(d) were crystalline $\mathrm{SiC}$ grains and a mixture of $\mathrm{Si}$ and $\mathrm{C}$, respectively. Thus, a single laser scan is insufficient to completely form $\mathrm{SiC}$. Crystalline phases of SiC were the $\beta$ phase at $P_{\mathrm{L}}=5,10 \mathrm{~kW} / \mathrm{cm}^{2}$, and $\alpha-\mathrm{SiC}$ at $P_{\mathrm{L}}=12 \mathrm{~kW} / \mathrm{cm}^{2}$. The $\alpha$ phase is a high-temperature phase of $\mathrm{SiC}$ formed above $2000^{\circ} \mathrm{C}$. In addition, the crystal phase composition of $\mathrm{SiC}$ was further evaluated by laser Raman spectroscopy. Figure 4 shows laser Raman spectra (NRS-7100, JASCO) recorded using an excitation wavelength of $532 \mathrm{~nm}$ in the $\mathrm{Si}-\mathrm{C}$ vibration range of 750 $850 \mathrm{~cm}^{-1}$ for $\mathrm{SiC}$ samples prepared using the various $P_{\mathrm{L}}$ values. For the sample prepared at $P_{\mathrm{L}}=5 \mathrm{~kW} / \mathrm{cm}^{2}$, no peak attributable to $\mathrm{Si}-\mathrm{C}$ vibration was detected. In the case of $P_{\mathrm{L}}=10 \mathrm{~kW} / \mathrm{cm}^{2}$, a strong peak corresponding to the TO mode of 3C-SiC ( $\beta$ phase) was observed at 796 $\mathrm{cm}^{-1}{ }^{16), 17)}$ Finally, shoulder peaks at 796 and $785 \mathrm{~cm}^{-1}$ observed for $P_{\mathrm{L}}=12 \mathrm{~kW} / \mathrm{cm}^{2}$ corresponded to the TO mode of $3 \mathrm{C}-\mathrm{SiC}$ ( $\beta$ phase) and the TO mode of $15 \mathrm{R}-\mathrm{SiC}$ $(\alpha$ phase), respectively.

In order to complete the reaction to form $\mathrm{SiC}$, laser scanning was repeated five times (the total irradiation time was about $1 \mathrm{~min}$ ). Surface and cross-sectional SEM images of the resulting sample are shown in Figs. 5(a) and 5(b), respectively. The matrix phase was not present at the surface, suggesting that the reaction was complete, and a dense 3- $\mu \mathrm{m}$-thick $\mathrm{SiC}$ layer was formed. Under the $\mathrm{SiC}$ layer, no changes were observed in the powder mixture, suggesting that the laser penetrated only several micrometers from the surface. Considering that the absorption coefficient of $\mathrm{C}$ is much higher than that of $\mathrm{Si}$, the $\mathrm{C}$ powder would be preferentially heated during Nd:YAG laser irradiation. Si would be melted by heat transfer from 


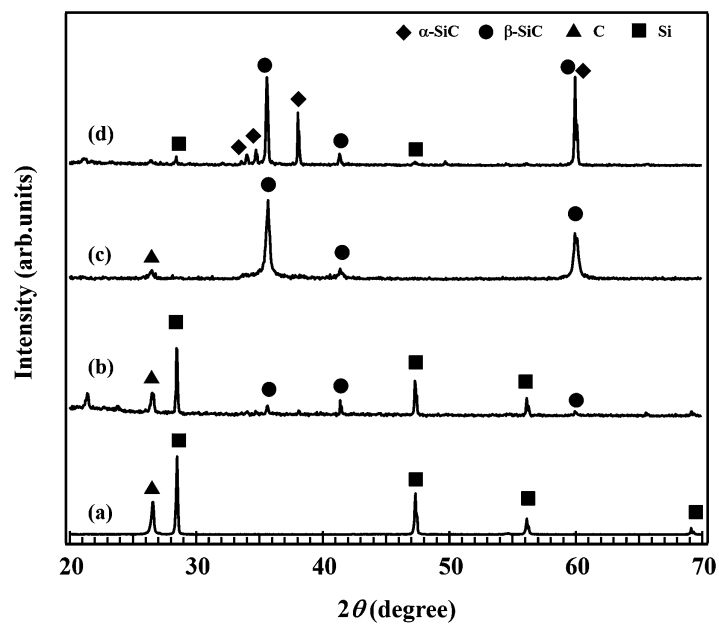

Fig. 3. XRD patterns of the (a) precursor powder; and RS-SiC samples sintered at (b) $5 \mathrm{~kW} / \mathrm{cm}^{2}$, (c) $10 \mathrm{~kW} / \mathrm{cm}^{2}$, and (d) $12 \mathrm{~kW} / \mathrm{cm}^{2}$.

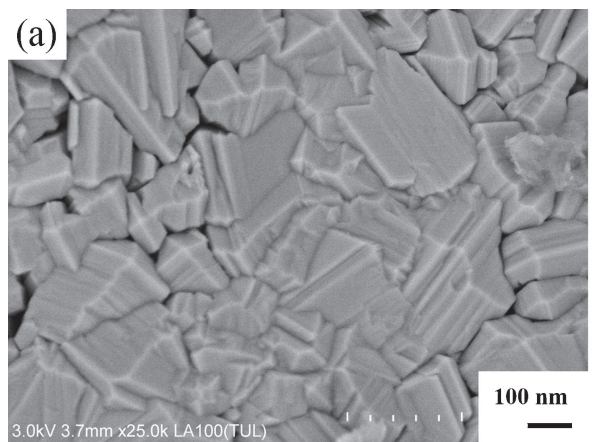

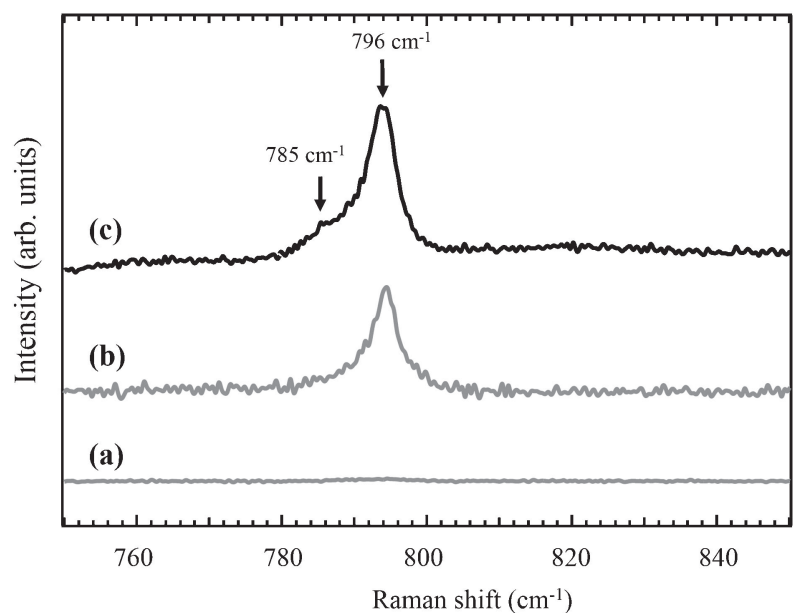

Fig. 4. Raman spectra of $\mathrm{RS}-\mathrm{SiC}$ prepared at $P_{\mathrm{L}}=$ (a) 5 $\mathrm{kW} / \mathrm{cm}^{2}$, (b) $10 \mathrm{~kW} / \mathrm{cm}^{2}$, and (c) $12 \mathrm{~kW} / \mathrm{cm}^{2}$.

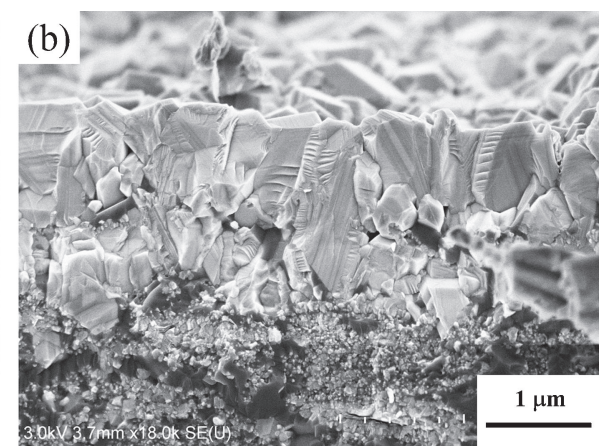

Fig. 5. (a) Surface and (b) cross-sectional SEM images of the RS-SiC sample produced at a laser power of $12 \mathrm{~kW} / \mathrm{cm}^{2}$ using five laser scans.

the $\mathrm{C}$ powder, where $\mathrm{SiC}$ subsequently forms via a liquidsolid reaction between molten Si and solid C.

Acknowledgement This work was supported by Council for Science, Technology and Innovation(CSTI), Crossministerial Strategic Innovation Promotion Program (SIP), "High-Value Added Ceramics Products Manufacturing Technologies"(Funding agency: NEDO).

\section{References}

1) R. Naslain, Compos. Sci. Technol., 64, 155-170 (2004).

2) W. J. Clegg, K. Kendall, N. McN. Alford, T. W. Button and J. D. Birchall, Nature, 347, 455-457 (1990).

3) S. R. Levine, E. J. Opila, M. C. Halbig, J. D. Kiser, M. Singh and J. A. Salem, J. Eur. Ceram. Soc., 22, 27572767 (2002).

4) T. Ishikawa, Y. Kohtoku, K. Kumagawa, T. Yamamura and T. Nagasawa, Nature, 391, 773-775 (1998).

5) R. Riedel, G. Passing, H. Schönfelder and R. J. Brook, Nature, 355, 714-717 (1992).

6) S. Suyama, T. Kameda and Y. Itoh, Diamond Relat. Mater., 12, 1201-1204 (2003).

7) W. E. Frazier, J. Mater. Eng. Perform., 23, 1917-1928
(2014).

8) D. Herzog, V. Seyda, E. Wycisk and C. Emmelmann, Acta. Mater., 117, 371-392 (2016).

9) C. Y. Yap, C. K. Chua, Z. L. Dong, Z. H. Liu, D. Q. Zhang, L. E. Loh and S. L. Sing, Appl. Phys Rev., 2, 041101 (2015)

10) H. J. Su, J. Zhang, L. Liu, J. Eckert and H. Z. Fu, Appl. Phys. Lett., 99, 221913-222915 (2011).

11) A. Gahler, J. G. Heinrich and J. Günster, J. Am. Ceram Soc., 89, 3076-3080 (2006).

12) X. Ma, J. Li, Z. Peng, B. Ma, X. Li, W. Pan and L. Qi, Cryst. Growth Des., 15, 5652-5655 (2015).

13) D. Gu, D. Dai, G. Zhang and H. Wang, Appl. Phys Lett., 101, 171603-171606 (2012).

14) Y. Xiong, J. E. Smugeresky, A. Julie and M. Schoenung, Mat. Sci. Eng. A-Struct., 493, 261-266 (2008).

15) S. Meyers, L. De Leersnijder, J. Vleugels and J.-P. Kruth, J. Eur. Ceram. Soc., 38, 3709-3717 (2018).

16) S. Nakashima and H. Harima, Phys. Status Solidi A 162, 39-64 (1997).

17) S. Sorieul, J.-M. Costantini, L. Gosmain, L. Thomé and J.-J. Grob, J. Phys. Condens. Matter, 18, 5235-5251 (2006). 